\title{
Anticancer property of gallic acid in A549, a human lung adenocarcinoma cell line, and possible mechanisms
}

\author{
Dharmendra K. Maurya, ${ }^{1}$ Nivedita Nandakumar ${ }^{2}$ and Thomas Paul Asir Devasagayam ${ }^{1, *}$ \\ ${ }^{1}$ Radiation Biology \& Health Sciences Division, Bhabha Atomic Research Centre, Trombay, Mumbai 400085, India \\ ${ }^{2}$ Padmashree Dr. D Y Patil University, Department of Biotechnology and Bioinformatics, C.B.D. Belapur, Navi Mumbai 400614, India
}

(Received 29 July, 2010; Accepted 10 September, 2010)

\begin{abstract}
Gallic acid is widely distributed in plants, fruits and foods with a range of biological activities. In the present study the possible mechanisms of gallic acid anticancer properties were explored in A549, a human lung adenocarcinoma cell line. Our study shows that it inhibited the A549 cell growth and decreased cell viability monitored at $\mathbf{2 4} \mathbf{~ h}$. It also inhibited cell proliferation in dose- and time-dependent manner as measured by 3-[4,5-methylthiazol-2-yl]2,5-diphenyl-tetrazolium bromide assay at 24 and $48 \mathrm{~h}$. Morphological examination of the cells after gallic acid treatment showed the typical feature of cell death such as cell shrinkage and rounding up of the cells. Clonogenic assay indicated that gallic acid treatments inhibited the colony formation. DNA fragmentation assay indicated the disappearance of the genomic DNA in dosedependent manner. To find out possible mechanisms, mitochondrial potential and intracellular reactive oxygen species were measured. It was observed that gallic acid treatment decreased mitochondrial membrane potential and increased intracellular reactive oxygen species. Further caspases activity was measured and it was found that gallic acid activated the caspase- 3 but not caspase-8 indicating the involvement of intrinsic pathway of cell apoptosis.
\end{abstract}

Key Words: apoptosis, adenocarcinoma, DNA damage, reactive oxygen species

W orldwide, lung cancer is the most common cancer in terms of both occurrence and mortality, with the highest rates in Europe and North America. Despite rapid advances in diagnostic and operative techniques, lung cancer remains one of the most difficult human malignancies to treat. The American Cancer Society estimates that 214,440 persons in the United States developed lung cancer in 2009, with 159,390 deaths. Lung cancerdependent deaths constituted $30 \%$ (men) and $26 \%$ (women) of the estimated total cancer-related deaths in 2009. Data indicate that while the overall incidence of lung cancer is declining, it continues to rise in women. ${ }^{(1)}$ The relative 5-year survival ratio of the patients that had lung or bronchus cancer from 1995 to 2001 was still quite low (15\%) and was not improved very much compared to the 1970 's $(12 \%)$. From the $1950 \mathrm{~s}$, the incidence of lung adenocarcinoma started to rise relative to other types of lung cancers. ${ }^{(2)}$

Recently, multiple new chemotherapeutic agents have been developed and some are in clinical trials. ${ }^{(3,4)}$ Although some of them have produced promising results, their therapeutic spectrum is narrow along with toxicity. This toxicity problem at therapeutic concentration induced scientists to search for anticancer compounds derived from natural sources such as phytochemicals. Keeping this in mind, the aim of the present paper is to explore the anticancer property of gallic acid (GA; 3,4 5-triphydroxyl-benzoic acid), a natural phytochemical, on A549 human lung cancer cell lines.

GA, a polyhydroxylphenolic compound, is widely distributed in various plants, fruits and foods. ${ }^{(5)}$ As far as the toxicity is concerned it has an $\mathrm{LD}_{50}$ dose of $5 \mathrm{~g} / \mathrm{kg}$ body weight in rats. ${ }^{(6)}$ GA has various biological activities such as anti-bacterial, antimelanogenic, anti-viral and anti-inflammatory ${ }^{(7-9)}$ besides anticancer activity in various cancer cells. ${ }^{(10-14)}$

\section{Materials and Methods}

Cell Cultures. A549, human lung adenocarcinoma cell line was maintained in DMEM (Dulbecco's modified Eagle's medium) (Himedia, Mumbai, India) supplemented with $10 \%$ fetal bovine serum (FBS), 100 units/ml penicillin and $100 \mu \mathrm{g} / \mathrm{ml}$ streptomycin (Himedia, Mumbai, India). The cells were incubated in $5 \% \mathrm{CO}_{2}$ humidified at $37^{\circ} \mathrm{C}$ for growth.

Evaluation of cell proliferation by MTT assay. The number of viable A549 cells after GA treatment was evaluated by the MTT (3-[4,5-methylthiazol-2-yl]-2,5-diphenyl-tetrazolium bromide) assay. In brief, A549 cells $\left(1 \times 10^{4}\right.$ cells/well $)$ were seeded in a 96-well plate and kept overnight for attachment. The next day the medium was replaced with fresh medium with various concentrations of GA $(100-400 \mu \mathrm{M})$ and cells were allowed to grow for 24 and $48 \mathrm{~h}$. Four hours before completion of incubation, $10 \mu \mathrm{l}$ of MTT $(10 \mathrm{mg} / \mathrm{ml})$ was added in each well. After completing the incubation, $100 \mu$ of solubilization buffer $(10 \%$ SDS with $0.01 \mathrm{~N} \mathrm{HCl})$ was added to each well and incubated overnight at room temperature. Color developed after the reaction was measured at $550 \mathrm{~nm}$ using Bio-Tek microplate reader.

Evaluation of A549 cell count and viability by trypan blue dye. In brief, $5 \times 10^{5}$ A549 cells were seeded in each well of 6-well plate and kept overnight for attachment. Next day old medium was replaced with fresh medium containing 0,100 and $200 \mu \mathrm{M}$ of GA and incubated for $24 \mathrm{~h}$. Following incubation, the supernatant pool was collected and adherent cells were trypsinized and collected. Cell viability was performed by the dye exclusion test with $0.5 \%$ trypan blue using a hemocytometer.

Clonogenic assay. In brief, $5 \times 10^{5}$ cells were seeded per well in a 6-well plate and allowed to attach overnight. The next day medium was replaced with fresh medium containing different concentration $(50,100,200 \mu \mathrm{M})$ of GA and incubated for $2 \mathrm{~h}$. Following incubation, cells were harvested by trypsinisation and counted. For clonogenic assay 250 A549 cells in $4 \mathrm{ml}$ medium

*To whom correspondence should be addressed. E-mail: tpad@barc.gov.in; tpauld2001@yahoo.co.in 
were seeded in 6-well plate and were incubated at $37^{\circ} \mathrm{C}$ for 12 days without any disturbances. Following incubation, the medium was removed and colonies were fixed and stained with $0.5 \%$ methylene blue (dissolved in $50 \%$ ethanol). Colony counting was performed with cellAnalyst software (AssaySoft, Inc., CA). The experiment was carried out twice in triplicates.

DNA Fragmentation analysis. In brief, $7.5 \times 10^{5}$ cells per well of 6-well plate were seeded and kept overnight for attachment. Next day old medium was replaced with medium containing $0,100,200$ and $400 \mu \mathrm{M}$ GA and incubated for $24 \mathrm{~h}$. Following incubation, cells were collected and washed with $1 \times$ PBS (phosphate buffered saline), resuspended in $100 \mu \mathrm{l}$ lysis buffer and incubated for $1 \mathrm{~h}$ at $50^{\circ} \mathrm{C} .10 \mu \mathrm{l}$ of RNase $(10 \mathrm{mg} / \mathrm{ml})$ was added to the lysate and further incubated for $1 \mathrm{~h}$ at $50^{\circ} \mathrm{C}$. The DNA samples were electrophoresed in a $1.8 \%$ agarose gel in TBE (Trisborate-EDTA) buffer ( $\mathrm{pH} \mathrm{8.0)}$. The DNA bands were visualized using a gel-doc system. The profile of the DNA band was analyzed using Scion Image analysis software.

Detection of intracellular ROS levels. The intracellular ROS (Reactive oxygen species) generation in A549 cells was investigated using the 2',7'-dichlorofluorescein-diacetate (DCFHDA) dye. For measuring the intracellular ROS in individual cells $5 \times 10^{5}$ cells were seeded on cover-slip in 6-well plate and incubated overnight for attachment. Next day old medium was replaced with fresh medium containing 0,100 and $200 \mu \mathrm{M}$ GA and left for $2 \mathrm{~h}$ at $37^{\circ} \mathrm{C}$. At the end of incubation cover-slip was removed from the culture plate and stained with $40 \mu \mathrm{M}$ DCFHDA for $30 \mathrm{~min}$. Excess of the dye was removed by washing with $1 \times$ PBS. Cover-slip was mounted on glass slide and images of the cells were captured using $40 \times$ objectives under fluorescence microscope.

For measuring total ROS level in the cells, $5 \times 10^{5}$ cells were seeded in a 6-well plate and allowed to attach overnight. The next day, medium was replaced by fresh medium containing 0,100 and $200 \mu \mathrm{M}$ of GA and allowed to incubate for 1 and $2 \mathrm{~h}$. Following incubations, the cells were harvested by trypsinization and washed with PBS and resuspended in PBS containing $10 \mu \mathrm{M}$ DCFH-DA. Equal number of cells in $100 \mu \mathrm{l}$ of DCFH-DA containing PBS were distributed in each well of 96-well fluorimetry plate and incubated at $37^{\circ} \mathrm{C}$ for $45 \mathrm{~min}$. The plate was read using an excitation of $485 \mathrm{~nm}$ and emission at $520 \mathrm{~nm}$ and graph was plotted denoting the change in ROS level.

Assessment of MMP. For assessing the mitochondrial membrane potential, A549 cells $\left(5 \times 10^{5} /\right.$ well $)$ were seeded in 6 well plates and incubated overnight for attachment. Next day old medium was replaced with fresh medium containing $200 \mu \mathrm{M}$ GA and incubated for $1 \mathrm{~h}$. Cells were collected by trypsinization and resuspended in $1 \mathrm{ml}$ of DiO6 (3,3'-dihexyloxacarboxyanine iodide) solution (40 $\mathrm{nM}$ DiO6 in $1 \times \mathrm{PBS})$ and incubated for $30 \mathrm{~min}$ at room temperature. Fluorescence intensity (Ex/Em: $488 / 525)$ was measured using microtiter plate reader.

Detection of caspase-3 levels. In brief, $1 \times 10^{6}$ A549 cells
A

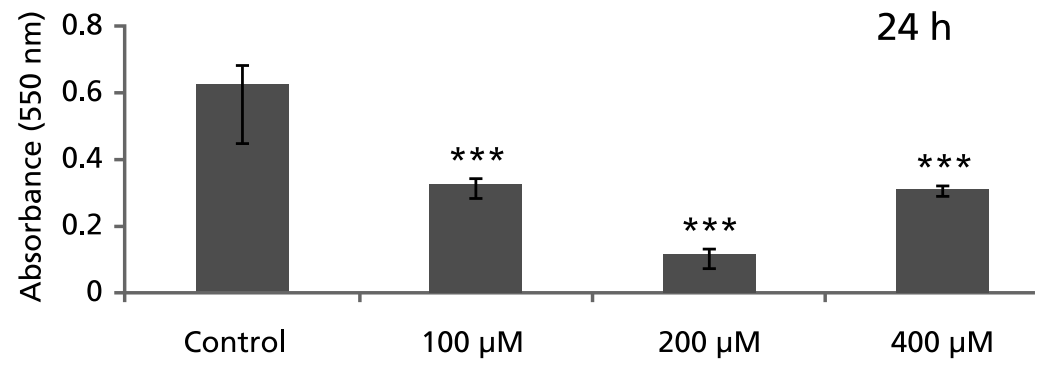

B

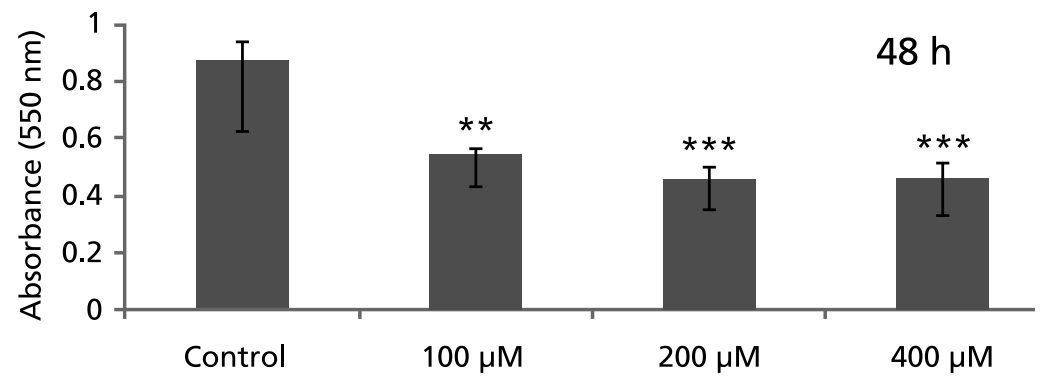

C
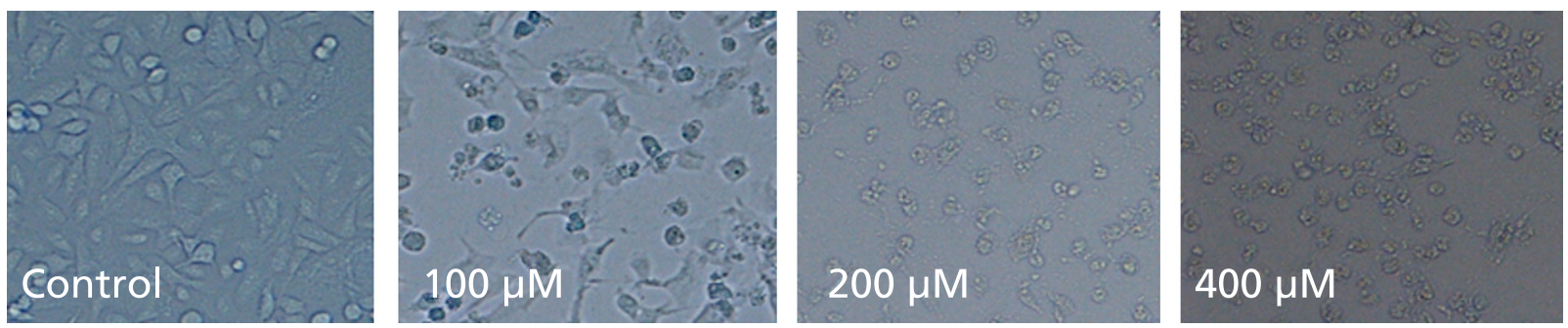

Fig. 1. Inhibition of A549 cell proliferation by gallic acid. In brief $1 \times 10^{4}$ cells were treated with $0,100,200$ and $400 \mu \mathrm{M}$ of gallic acid. A: $24 \mathrm{~h}$ MTT assay, B: 48 h MTT assay. C: Morphology of A549 cells treated with different concentrations of gallic acid. $* \star *: p<0.001$. 


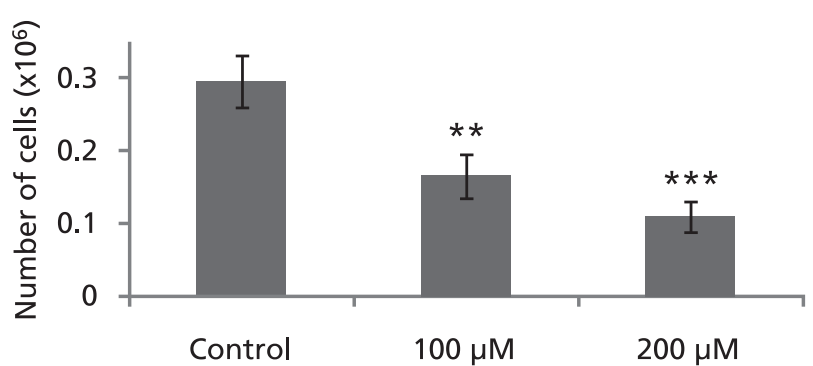

B

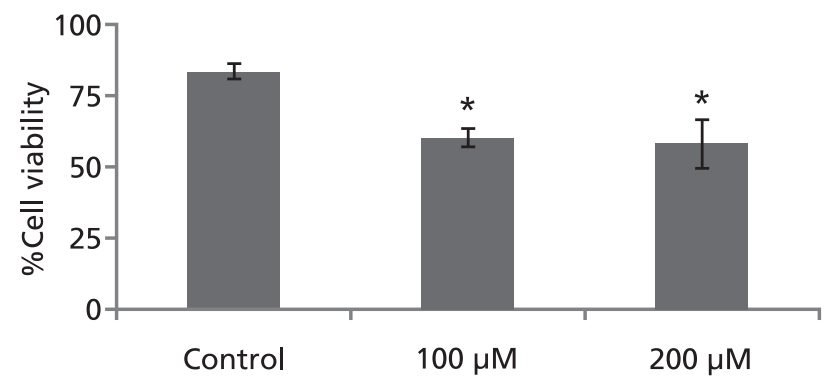

Fig. 2. Effect of gallic acid on A549 cell count and viability. A: Graph showing cell counting result and, B: Graph showing \% cell viability. *: $p<0.05$; $* *: p<0.05 ; * * *: p<0.001$.

were seeded in a 6-well plate and allowed to attach overnight. The next day medium was replaced by fresh medium containing 0,100 and $200 \mu \mathrm{M}$ of GA and incubated for 1,3 and $6 \mathrm{~h}$. At the end of incubations, cells were collected by trypsinization and washed twice in PBS. Cell pellet was resuspended in $75 \mu \mathrm{l}$ of $1 \times$ lysis buffer and incubated on ice for 15-20 min. Cell lysate were centrifuged at $20,000 \mathrm{rpm}$ for $15 \mathrm{~min}$ at $4^{\circ} \mathrm{C}$. Pellet was discarded and supernatant was transferred to new tubes and stored at $-80^{\circ} \mathrm{C}$ till analysis. The supernatants were used for estimation of caspase3 as instructed by the manufacturer in 96-well microtiter plate.

Statistical analysis. All values are expressed as means $\pm \mathrm{SE}$. Statistical significance was set at ${ }^{*} p<0.05 ; * * p<0.05 ; * * * p<0.001$.

\section{Results}

GA inhibits A549 cells growth and proliferation. As shown in Fig. 1 GA inhibited A549 cell proliferation in doseand time-dependent manner. From Fig. 1 it is also clear that this cell growth inhibition was limited to $200 \mu \mathrm{M}$. After $200 \mu \mathrm{M}$ there was not much cell growth inhibition. From examination of A549 cells morphology at $24 \mathrm{~h}$ after 100,200 and $400 \mu \mathrm{M}$ GA treatment it was observed that cells started shrinking showing the symptoms of the cell death. Further, total cell count and the cell viability were measured after treating cells with GA for $24 \mathrm{~h}$. From Fig. 2A, it was clear that the total cell count started decreasing in the GA treated group and this effect was observed in a concentrationdependent manner. As shown in Fig. 2B, the percent viability of cells decreased with GA treatment but not in a concentrationdependent manner.

GA inhibited A549 colony growth. The anticancer property of GA was also examined by clonogenic assay. The colony is defined to consist of at least 50 cells. As shown in Fig. 3, GA significantly decreased A549 colony growth in a concentrationdependent manner.

GA induces cellular DNA fragmentation. From Fig. 4, it is clear that GA leads to a concentration dependent decrease in the total genomic DNA. However, no clear DNA ladder pattern was observed in this cell line.

GA induced intracellular ROS in A549 cells. As shown in Fig. 5A-C, GA treatment induced the ROS level in cell as measured by fluorescence microscopy study at individual cell level. From these cell images it is clear that the fluorescence intensity of individual cells increased in a concentration-dependent manner indicating ROS generation by GA. Further, total cellular ROS was measured fluorimetrically at 1 and $2 \mathrm{~h}$ post treatment with GA and this observation collaborated well with fluorescence microscopy results (Fig. 5D).

GA disrupts mitochondrial membrane potential in A549 cells. Since it is known that increase in ROS level disrupt the MMP to execute the apoptosis, the third experiment was

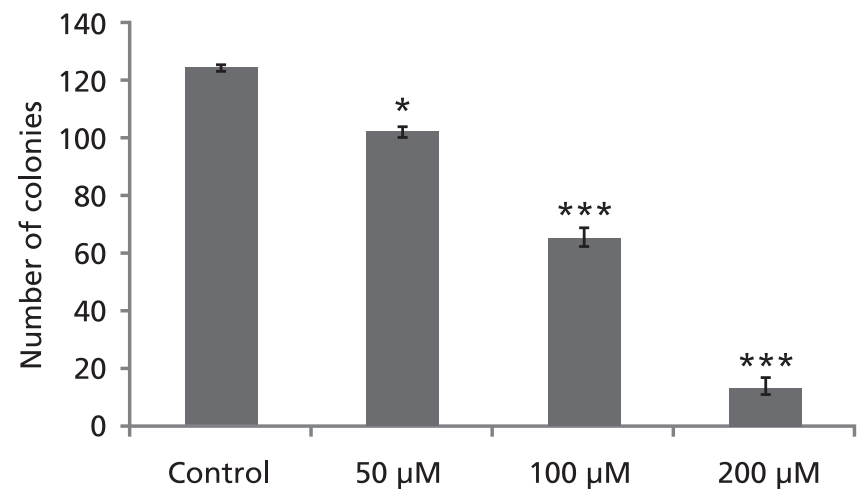

Fig. 3. Effect of gallic acid on A549 cells in clonogenic assay. The graph shows the number of colonies formed on the culture plate 12 days after treatment. *: $p<0.05 ; * * *: p<0.001$.

carried out to find out the possible mechanisms was the measurement of MMP. As shown in Fig. 6, $1 \mathrm{~h}$ incubation of cells with GA marginally disrupted the MMP.

GA induces caspase-3 in A549 cells. Since disruption of MMP leads to induction of apoptosis by intrinsic pathway via caspase- 3 induction, in the next experiment the level of caspase- 3 was measured and it was found that treatment of A549 cells with GA induced the caspase-3 (Fig. 7) but not caspase- 8 (data not shown) to execute the process of apoptosis.

\section{Discussion}

The relationship between diet and cancers has been implicated in several epidemiological studies. The cancer incidence is significantly lower in people whose diet consists largely of fruits and vegetables than people whose diet consists of mainly animal products. ${ }^{(15)}$ The present paper focused on evaluating the effects of GA, a dietary phytochemical on A549, human lung adenocarcinoma cell line in relation to cell growth inhibition, apoptosis and their underlying mechanisms.

To determine the inhibitory concentration of GA on A549 cells, cell proliferation and cell viability was determined. It was observed that exposure to GA for $24 \mathrm{~h}$, A549 cell growth was inhibited as it is clear from MTT assay and direct cell count (Figs. 1 and 2). The morphological changes in cells clearly indicate that cells undergo apoptosis at $24 \mathrm{~h}$ after incubation with the concentration of GA chosen based on the MTT assays (Fig. 1C). To study reproductive cell death further clonogenic assay was carried out. Our finding shows that GA dose dependently inhibited the A549 colony formation as compared to the 

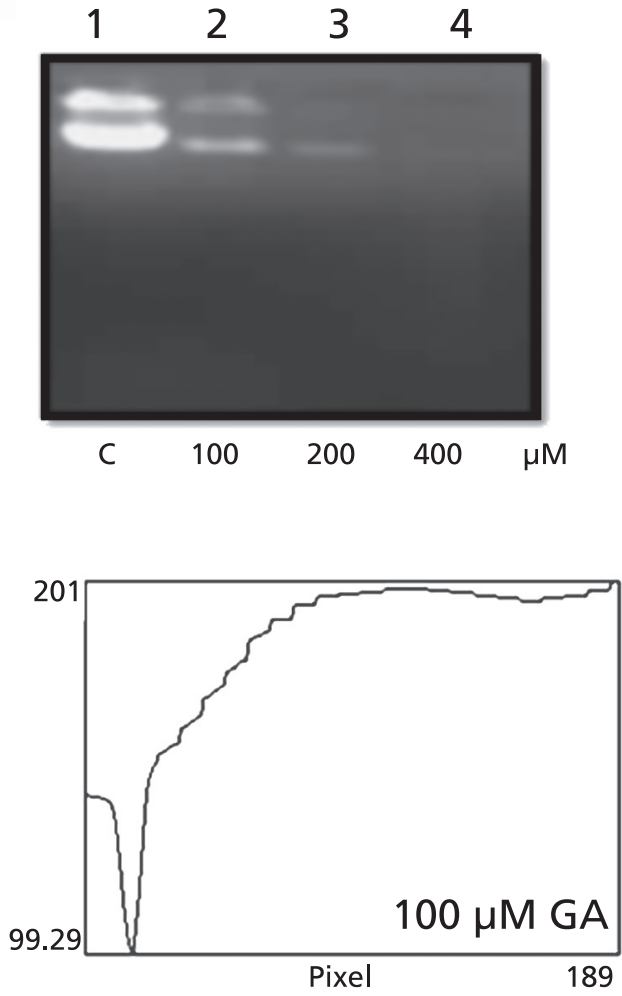

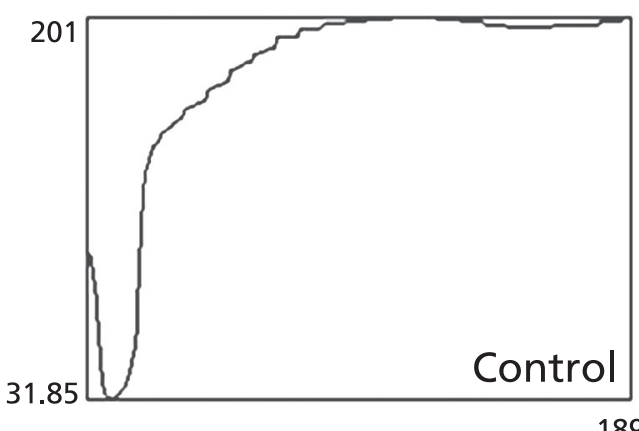

189

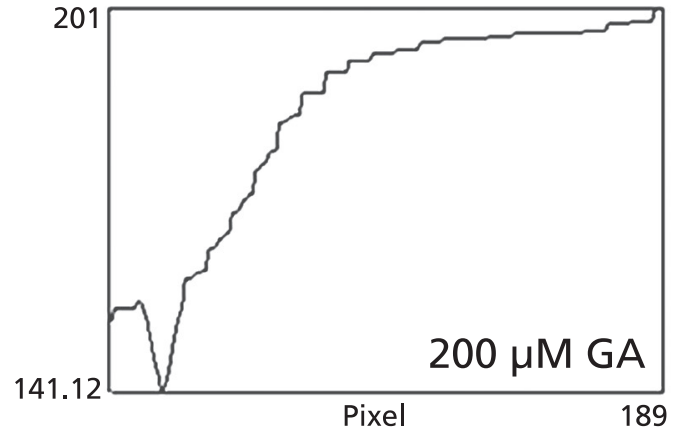

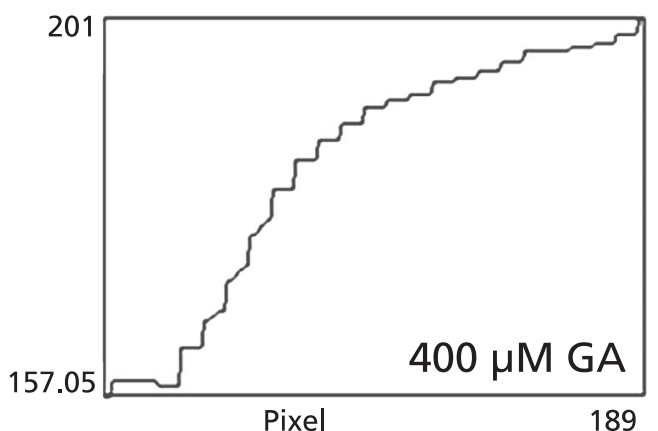

Fig. 4. DNA fragmentation assay. Lane 1: control cells, Lane 2, Lane 3, Lane 4 are 100, 200 and $400 \mu \mathrm{M}$ gallic acid treated cells respectively depicting loss in genomic DNA.

control cells (Fig. 3). This indicates that GA decreases the potential of individual cells to form a colony and thereby acts as an anti-cancer drug. This finding well corroborated with our cell proliferation and cell count studies. Further DNA fragmentation assay was performed for study of the apoptosis induction by GA. Here we did not find clear DNA ladder pattern in A549 cells but the concentration dependent degradation of genomic DNA was observed in cells treated with GA (Fig. 4).

To gain insight into the molecular mechanism involved in GA induced apoptosis, the level of ROS, change in MMP and the activation of caspase- 3 were assessed in A549 cells. GA has been reported to have both pro-oxidant and antioxidant properties. ${ }^{(16,17)}$ Accumulation of ROS coupled with an increase in oxidative stress has been implicated in the pathogenesis of several disease including cancers. Increasing evidence suggests that apoptosis induced by GA is associated with oxidative stress derived from ROS and mitochondrial dysfunction..$^{(11,18)}$ Our result indicates that the intracellular ROS levels were significantly increased in A549 cells treated with GA for 1 and 2 h (Fig. 5). Although cancer cells have an increased ROS as compared to healthy cells, the increased ROS is believed to be responsible for many novel cancer cell properties including loss of cell senescence. However, an increase of ROS beyond threshold would result in irreversible DNA damage that would translate in the activation of apoptosis pathway. GA has shown a 2 fold increase in ROS as compared to the control cells. This is in correlation with other reports that provide substantial evidence that apoptotic cells generally exhibit an increase in ROS levels. Loss in membrane potential is another major biochemical change in cells undergoing apoptosis. Our study showed that there is a $31 \%$ decrease in the MMP in control cells compared to $200 \mu \mathrm{M}$ GA treated cells after $1 \mathrm{~h}$ of incubation (Fig. 6). Caspases activity was quantified by colorimetric assay. Although we estimated both caspase- 3 and -8 , our studies have shown a clear increase in the caspase- 3 activity (Fig. 7) but not the caspase-8 (data not shown), indicating that GA induced apoptosis in A549 cells is by the activation of caspase- 3 pathway (intrinsic pathway). The maximum activation of caspase- 3 was seen at 1 and $3 \mathrm{~h}$ and showed a slight decrease compared to earlier values at $6 \mathrm{~h}$. 

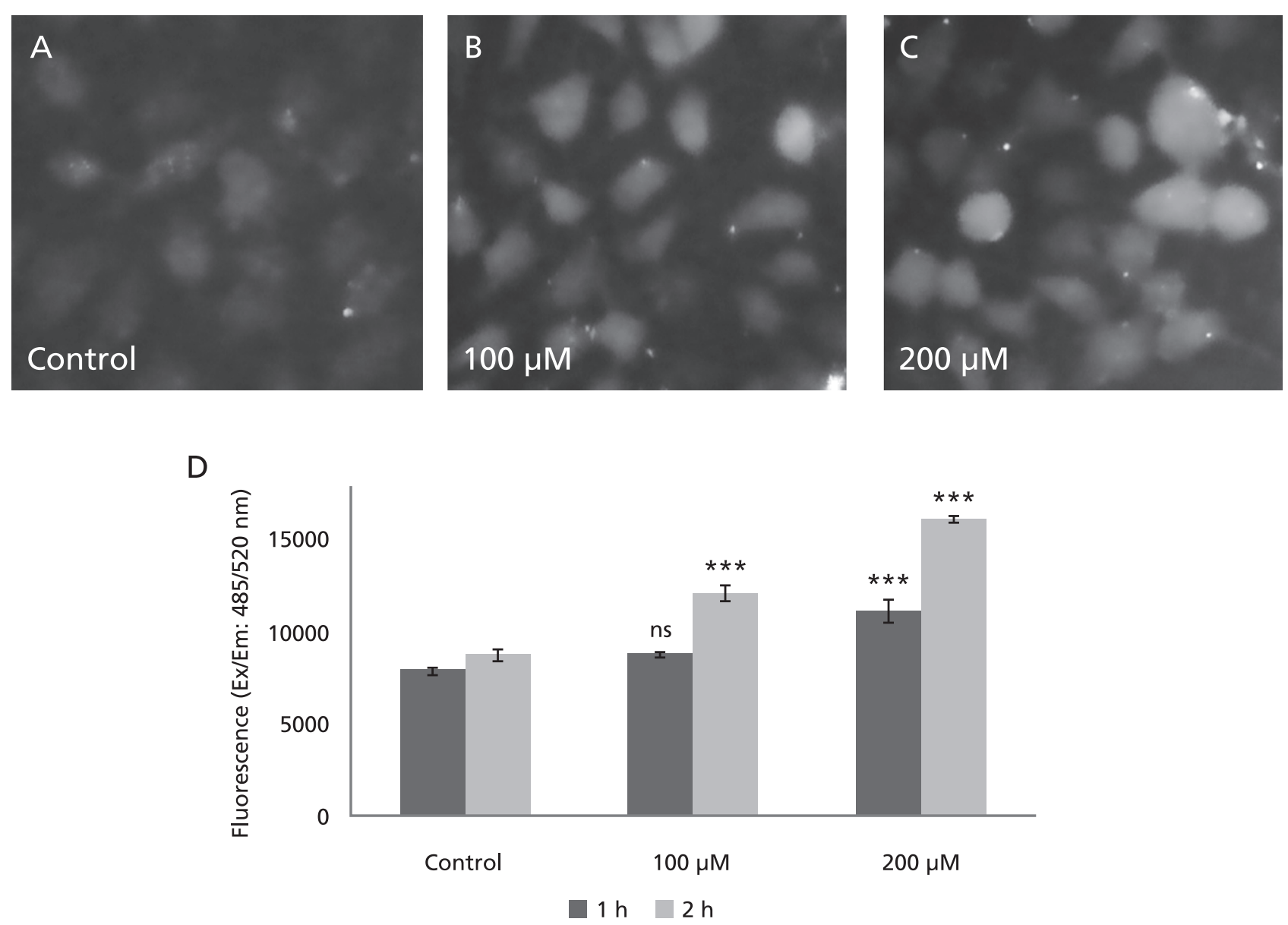

Fig. 5. Intracellular ROS level in A549 cells after gallic acid treatment. A-C: The A549 cell images treated with 0,100 and $200 \mu \mathrm{M} \mathrm{gallic}$ acid for $2 \mathrm{~h}$ and capture using fluorescence microscope at $40 \times$ objective. D: The level of ROS in A549 cells treated with 0,100 and $200 \mu \mathrm{M}$ gallic acid for 1 and $2 \mathrm{~h}$ as measured by fluorimetry. $* * *: p<0.001$.

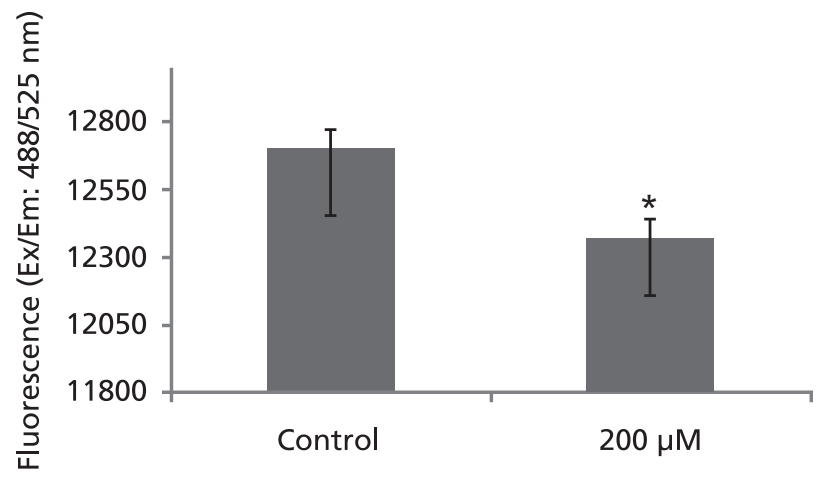

Fig. 6. Loss in mitochondrial membrane potential: graph represents the change in mitochondrial potential in A549 cells treated with $200 \mu \mathrm{M}$ gallic acid for $1 \mathrm{~h}$ as measured by fluorimetry. *: $p<0.05$.

The radioprotective properties of GA have been determined by an independent study in our laboratory. ${ }^{(19)}$ Even administration of GA alone has been shown to have anti-tumor effect and provides evidence that GA can be used alone or as a combination therapy with radiation. Being a dietary constituent it is readily available in natural form and is not expensive in terms of purification of the compound. Since GA is found in micro molar concentrations

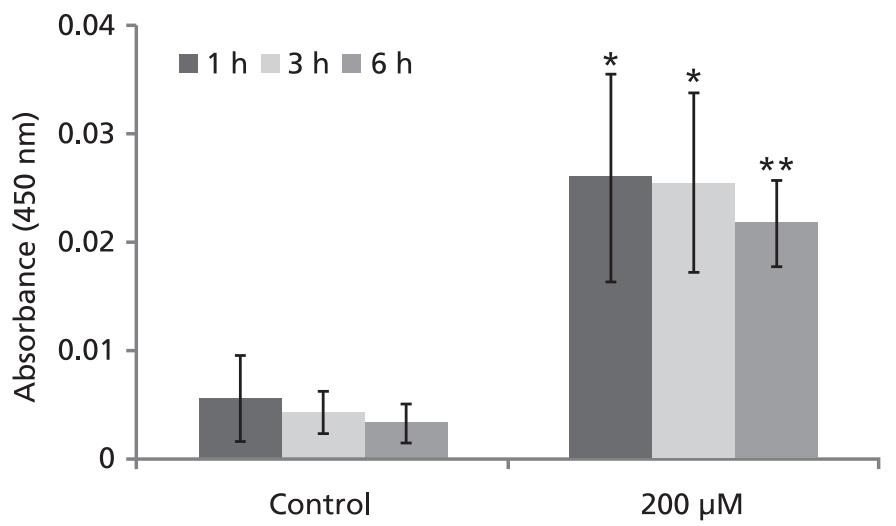

Fig. 7. Changes in the level of Caspase-3 activity at 1, 3 and $6 \mathrm{~h}$ after gallic acid treatments. *: $p<0.05 ; * *: p<0.05$.

in the human urine, it rules out any possible cytotoxicity to neighboring healthy cells. Hence GA provides with an ideal choice in the treatment of lung cancer.

In conclusion our studies proves that GA induces cell death in A549 lung carcinoma cells in a dose dependent manner and induced apoptosis by elevation ROS, disrupting MMP, and activating caspase-3. 


\section{Abbreviations}

GA

3,4 5-triphydroxyl-benzoic acid

MTT 3-[4,5-methylthiazol-2-yl]-2,5-diphenyl-tetrazolium bromide

DMEM Dulbecco's modified Eagle's medium
FBS

PBS

TBE

ROS

DCFH-DA 2',7'-dichlorfluorescein-diacetate

Dio6 3,3'-dihexyloxacarboxyanine iodide

\section{References}

1 Jemal A, Siegel R, Ward E, Hao Y, Xu J, Thun MJ. Cancer statistics, 2009. CA Cancer J Clin 2009; 59: 225-249.

2 Chen F, Bina WF, Cole P. Declining incidence rate of lung adenocarcinoma in the United States. Chest 2007; 131: 1000-1005.

3 Lynch TJ, Adjei AA, Bunn PA. Novel agents in the treatment of lung cancer: conference summary statement. Clin Cancer Res 2004; 10: S4199-S4204.

4 Johnson DH, Schiller JH. Novel therapies for the treatment of non-small cell lung cancer. Cancer Chemother Biol Response Modif 2002; 20: 763-786.

5 Niemetz R, Gross GG. Enzymology of gallotannin and ellagitannin biosynthesis. Phytochemistry 2005; 66: 2001-2011.

6 Shahrzad S, Aoyagi K, Winter A, Koyama A, Bitsch I. Pharmacokinetics of gallic acid and its relative bioavailability from tea in healthy humans. J Nutr 2001; 131: 1207-1210.

7 Kang MS, Oh JS, Kang IC, Hong SJ, Choi CH. Inhibitory effect of methyl gallate and gallic acid on oral bacteria. J Microbiol 2008; 46: 744-750.

8 Kratz JM, Andrighetti-Fröhner CR, Leal PC, and et al. Evaluation of antiHSV-2 activity of gallic acid and pentyl gallate. Biol Pharm Bull 2008; 31: 903-907.

9 Kim SH, Jun CD, Suk K, and et al. Gallic acid inhibits histamine release and pro-inflammatory cytokine production in mast cells. Toxicol Sci 2006; 91: 123-131.

10 Ji BC, Hsu WH, Yang JS, and et al. Gallic acid induces apoptosis via caspase-3 and mitochondrion-dependent pathways in vitro and suppresses lung xenograft tumor growth in vivo. J Agric Food Chem 2009; 57: 75967604.
11 Inoue M, Sakaguchi N, Isuzugawa K, Tani H, Ogihara Y. Role of reactive oxygen species in gallic acid-induced apoptosis. Biol Pharm Bull 2000; 23: 1153-1157.

12 Kaur M, Velmurugan B, Rajamanickam S, Agarwal R, Agarwal C. Gallic acid, an active constituent of grape seed extract, exhibits anti-proliferative, pro-apoptotic and anti-tumorigenic effects against prostate carcinoma xenograft growth in nude mice. Pharm Res 2009; 26: 2133-2140.

13 Kawada M, Ohno Y, Ri Y, and et al. Anti-tumor effect of gallic acid on LL-2 lung cancer cells transplanted in mice. Anticancer Drugs 2001; 12: 847-852.

14 Faried A, Kurnia D, Faried LS, and et al. Anticancer effects of gallic acid isolated from Indonesian herbal medicine, Phaleria macrocarpa (Scheff.) Boerl, on human cancer cell lines. Int J Oncol 2007; 30: 605-613.

15 Devasagayam TP, Tilak JC, Boloor KK, Sane KS, Ghaskadbi SS, Lele RD. Free radicals and antioxidants in human health: current status and future prospects. J Assoc Physicians India 2004; 52: 794-804.

16 Sakagami H, Satoh K. Prooxidant action of two antioxidants: ascorbic acid and gallic acid. Anticancer Res 1997; 17: 221-224.

17 Strlic M, Radovic T, Kolar J, Pihlar B. Anti- and prooxidative properties of gallic acid in fenton-type systems. J Agric Food Chem 2002; 50: 6313-6317.

18 Serrano A, Palacios C, Roy G, and et al. Derivatives of gallic acid induce apoptosis in tumoral cell lines and inhibit lymphocyte proliferation. Arch Biochem Biophys 1998; 350: 49-54.

19 Gandhi NM, Nair CK. Protection of DNA and membrane from gamma radiation induced damage by gallic acid. Mol Cell Biochem 2005; 278: $111-$ 117 